\title{
Yield Variation among Clones of Lowbush Blueberry as a Function of Genetic Similarity and Self-compatibility
}

\author{
Daniel J. Bell, Lisa J. Rowland ${ }^{\mathbf{1}}$, and John Stommel \\ USDA/ARS, Henry A. Wallace Beltsville Agricultural Research Center, Genetic Improvement of \\ Fruits and Vegetables Laboratory, 10300 Baltimore Avenue, Building 010A, BARC-West, Beltsville, \\ MD 20705 \\ Frank A. Drummond \\ University of Maine, School of Biology and Ecology, Deering Hall, Room 305, Orono, ME 04473
}

Additional INDEX words. combining ability, diallel, EST-PCR, genetic load, heritability, Vaccinium angustifolium

\begin{abstract}
Two types of field hand crosses (pairwise touching-neighbor and a full $5 \times 5$ diallel, Griffing's Model 2 , Method 3) were performed in combination with genetic similarity estimations of mating partners using expressed sequence tag-polymerase chain reaction molecular markers to elucidate genetic factors underlying yield variations among clones (genotypes) of lowbush blueberry (Vaccinium angustifolium) in two managed fields in Maine. Genetic similarity values for touching pairs ranged from 0.308 to 0.765 . Based on pairwise touching-neighbor crosses, no evidence was found for yield being affected by genetic similarity. However, self-fertility of clones was a significant positive predictor of outcross yields. The calculation of lethal equivalents, derived from selfing to outcross ratios, showed a large range in genetic load among clones and a higher average load than that previously reported in the related highbush blueberry $(V$. corymbosum). The diallel experiment revealed significant general and specific combining ability for all three post-pollination yield traits measured (proportion fruit set, mean mature seed per pollination, and mean berry weight per pollination). Narrow-sense heritability estimates for all three yield traits were moderately high $\left(\mathrm{h}^{2}=\mathbf{0 . 5 8}, 0.46\right.$, and 0.56 , respectively). It is concluded that phenotypically screening for selfcompatible clone yield attributes could be useful in identifying germplasm candidates for breeding and propagation.
\end{abstract}

Lowbush blueberry is an important crop in Maine, Maritime Canada, and Quebec. In Maine, the crop is currently harvested on over 24,000 ha (Yarborough, 2009a) with a 2008 yield of nearly 40.8 million kilograms and a harvest value of $\approx \$ 75$ million (Yarborough, 2009b). North American lowbush blueberry production area has increased by 33\% from 1993 to 2003 to $\approx 70,000$ ha (Strik, 2006) with the majority of this rise the result of an increase in Canadian production (Yarborough, 2009a). North American acreage yielded a total of 100.7 million kilograms of fruit in 2003. Projections suggest that lowbush fruit production in North America will increase 10\% by 2013 (Strik, 2006).

Approximately $1.0 \%$ of the lowbush blueberry crop is used fresh with the rest delivered to market as processed blueberry products. Blueberries have been shown to have one of the highest antioxidant activities among fruit tested, including cranberries (Vaccinium macrocarpon), apples (Malus $\times$ domestica), and red and green grapes (Vitis vinifera) (Wolfe and Liu, 2007). Antioxidants have been linked with numerous health benefits, including reduced eye strain, prevention of macular degeneration, anticancer activity, and reduced risk of heart disease (Cho et al., 2004; Kalt et al., 2007; Rimando et al.,

Received for publication 2 Mar. 2010. Accepted for publication 15 Apr. 2010. We would like to thank Judy Collins for her suggestions and general support over this multi-year study. Also, a thanks to Elizabeth Ogden and numerous students for experimental execution and data collection. Finally, a special thanks to Kathy Haynes for her expertise in the interpretation of the diallel statistics and method of calculating tetraploid heritability. This is Maine Agricultural and Forest Experiment Station Publication Number 3124

${ }^{1}$ Corresponding author. E-mail: Jeannine.Rowland@ars.usda.gov.
2004). A key component of blueberry marketing emphasizes increasing public awareness of these benefits.

Lowbush blueberry has a clonal growth habit; it is a prostrate shrub that spreads through an underground network of rhizomes. Individual genotypes, which are termed clones, make up the visually distinctive mosaic patchwork evident in lowbush blueberry fields. Currently, these fields are not sown. Clones originate from wild seed during reclamation of abandoned lands from seed banks, which have resulted from animalmediated dispersal processes. Cultivation practices to date have focused on optimizing growth, namely by fertilization, irrigation, and prevention of losses resulting from diseases, weeds, and insect pests (Drummond, 2000; Yarborough, 2009a). In recent years, pollination has been enhanced by the use of rented honeybees (Apis mellifera) (Drummond, 2002). Numerous cultural practices, including the use of pre-emergence herbicides and fertility optimization, have increased harvest yields in Maine by a factor of four during the last two decades (Yarborough, 2004, 2009a). Despite these gains, there remains much to be learned regarding the specific genetic basis of crosscompatibility factors affecting yield among these near-neighbor pollen exchangers (Aras et al., 1996; Turner et al., 1982). As a result of this lack of knowledge, the difficulty and expense of propagating and establishing new plants in the field, and an industrywide concern over preserving the wild image of lowbush blueberry, few attempts have been made to increase yields by altering stand composition through new plantings, roguing out of poor yielding clones, or filling bare areas of fields.

Individual genotypes of lowbush blueberry, growing proximally under similar, managed environmental conditions, 
exhibit dramatic differences in berry yield. In a multiyear study, Hepler and Yarborough (1991) demonstrated that the yield of 100 randomly selected clones ranged from 300 to $17,000 \mathrm{~kg} \cdot \mathrm{ha}^{-1}$ $\left(\right.$ mean $\left.=7726 \mathrm{~kg} \cdot \mathrm{ha}^{-1}\right)$ and that clones tended to stay within their yield rank over time. In a more recent 2-year study of 40 clones, individual clone yield varied somewhat by year, but again the rank order of clones from highest to lowest yielders over 2 consecutive fruiting years did not change (Bell, 2009). Understanding these dramatic differences in yield among similarly managed clones in the same fields is the focus of this research.

Lowbush blueberry $(2 n=4 x=48)$ is phenotypically and genetically highly polymorphic (Bell et al., 2008). It is possibly an autotetraploid and exhibits tetrasomic inheritance (Hokanson and Hancock, 1993). It is hermaphroditic, extremely long-lived, and a predominantly outcrossing woody perennial (Vander Kloet, 1978). Some researchers have characterized lowbush blueberry as almost wholly self-incompatible (Aalders and Hall, 1961; Vander Kloet, 1976), whereas others (Wood, 1968) have reported notable exceptions. Although the species possesses binucleate pollen and a wet stigma, which are two important hallmark traits of gametophytic self-incompatibility (GSI), to our knowledge, no evidence of stylar RNases inhibiting or destroying self pollen tubes (GSI mechanism) has ever been documented. On the contrary, inbreeding depression is considered the predominant selective agent for maintenance of outcrossing in this species (Hokanson and Hancock, 2000). Hall et al. (1979) demonstrated that pollen from different donors can dramatically impact the levels of fruit and seed set. Little knowledge of the genetic relationship among breeding pairs in studies such as these precluded further insights into how these kinds of genetic factors might influence plant yield. Such knowledge is imperative to experimentally test hypotheses regarding effects of parental relationship and inbreeding depression on yield. It has recently been proposed that high kinship levels may cause embryo and fruit abortion within localized patches of clones within fields (Myra et al., 2004).

Fortunately, the genetic relationship between clones may now be estimated using molecular markers. Expressed sequence tag-polymerase chain reaction (EST-PCR) markers originally developed for use in highbush blueberry (Rowland et al., 2003a, 2003b, 2003c) have recently been shown to be effective in lowbush blueberry for fingerprinting genotypes and for estimation of genetic relatedness between clones (Bell et al., 2008). Bell et al. (2008) demonstrated that relationships estimated from EST-PCR markers accurately reflected the parent-progeny and full/half-sib genetic relationships from a known pedigree of four lowbush blueberry clones. These markers have been further used to characterize a random spatial genetic structure among clones within fields (Bell et al., 2009).

In the present study, our goal was to test whether genetic similarity levels affect yield and also whether other genetic factors such as self-fertility and/or combining abilities are involved. Two specific experimental designs using field hand crosses (pairwise touching-neighbor and a $5 \times 5$ diallel) were performed and coupled with genetic similarity calculations from EST-PCR markers of breeding partners to better understand the genetic factors underlying these yield differences. We focused on the genetic requirements for successful berry production and avoided pollen limitation questions by applying appropriate and sufficient amounts of single-source pollen in hand crosses. Questions of whole plant yield (relative stem and floral densities among clones) and pollen quantity (relative pollinator density and effectiveness) were also not addressed in this study, because we measured fruit set from the same numbers of hand crosses in all clones. We tested three contingent and possibly integrated hypotheses: 1 ) genetic similarity among cross participants causes localized depressions in yield; 2) differential genetic loads carried among clones may be yield determinants; and 3) that general (GCA) and specific combining abilities (SCA) can explain yield variation among clones.

\section{Materials and Methods}

\section{Study sites and clone selection}

We selected two managed fields $\approx 12.5 \mathrm{~km}$ apart in the blueberry barrens area of northeastern coastal Maine. The first site was the University of Maine, Blueberry Hill Farm, Jonesboro, ME (lat. $44^{\circ} 38^{\prime} \mathrm{N}$, long. $67^{\circ} 38^{\prime} \mathrm{E}$ ). The second was a privately managed field near Cherryfield, ME, designated here as the Columbia site (lat. $44^{\circ} 40^{\prime} \mathrm{N}$, long. $67^{\circ} 52^{\prime} \mathrm{E}$ ). Healthy, vigorous clones were chosen ranging from 3 to $10 \mathrm{~m}$ in diameter for use in crosses and marked at their centers with a precision $( \pm 1 \mathrm{~m})$ global positioning system (Trimble Pathfinder $^{\circledR}$; Trimble Navigation, Sunnyvale, CA).

\section{Hand pollinations}

For all hand pollinations performed during the 3 years of this study, experimental stems were bagged or caged before flowers opened. Preliminary studies have revealed that caged flowers set no fruit and thus, although some ants are present, their relative pollinating impact, compared with the high density of rented honeybees during peak bloom when field pollinations were carried out, was judged to be minimal. Several factors were considered in the decision not to emasculate flowers in the field. These were: 1) in the absence of pollinator access, zero fruit set results (Bell, 2009); 2) we applied sufficient outcross pollen; and 3) the highly effective floral morphology, which separates male and female reproductive organs and thus prevents the pollination of a flower by its own pollen. Stems containing flowers for pollen collection were cut and flowers were allowed to bench dry at room temperature. A protocol of visually selecting adjacent stems, one by one and localized near the center of the donor clone, was used to assure that all stems were collected from the same genotype. Occasionally, rogue genotypes were identified within a clone (by differences in the color and hue of foliage and flowers). These were not used for pollen collection. Pollen was collected from freshly opened flowers into glass petri dishes by sonication using a tuning fork. Flowers from which pollen was collected were destructively harvested and not used for hand pollinations. Pollen was applied to stigmas using a small brush in sufficient, nonlimiting amounts [determined by a preliminary dosage study (Bell, 2009)]. In all 3 years of the study, all newly opened blossoms were pollinated over $\approx 12$ to $14 \mathrm{~d}$ during bloom, which starts approximately in mid-May in Maine.

\section{Experimental field hand crosses: description}

Diallel. The first of two field hand pollination designs was a $5 \times 5$ diallel. This is a factorial, reciprocal crossing design in which combining abilities can be estimated. The selection of this kind of diallel was based on our experimental focus, which was to make inferences about the wild population at large based on an experimental subset of five randomly selected clones from the field. The model appropriate for this is Griffing's 
Model 2 (random model). Because inbreeding depression is considered prevalent in lowbush blueberry, we chose Griffing's Method 3, which does not include the S1 (self) crosses. Self crosses in an inbreeding susceptible species do not accurately reflect the parental performance and their inclusion can inflate variance estimates and possibly underestimate the GCA/SCA ratios and, thus, heritability estimates (Shattuck et al., 1993; Wright, 1985). Also, because transformed data can cause distortions of the GCA/SCA ratios, we did not transform our yield measurements for the diallel analyses (Quimio and Zapata, 1990; Shattuck et al., 1993; Widstrom et al., 1992). The application software used was DIALLEL-SAS-05 (Zhang and Kang, 1997; Zhang et al., 2005) and was run using SAS (Version 9.2; SAS Institute, Cary, NC). Narrow-sense heritability, adjusted for an autotetraploid (Ortiz and Golmirzaie, 2002), was calculated as $h^{2}=\sigma^{2}{ }_{A} /\left(\sigma_{A}^{2}+\sigma^{2}{ }_{D}+\sigma^{2}{ }_{\mathrm{e}} / \mathrm{r}\right)$; in which $\sigma_{\mathrm{A}}^{2}=4 \sigma_{\mathrm{GCA}}^{2}-(2 / 3) \sigma_{\mathrm{SCA}}^{2}, \sigma_{\mathrm{D}}^{2}=6 \sigma_{\mathrm{SCA}}^{2}, \sigma_{\mathrm{e}}^{2}=$ model error, and $\mathrm{r}=$ replications.

Five focal pollen recipients for the diallel study were randomly selected and located $\approx 5$ to $30 \mathrm{~m}$ apart at the Blueberry Hill Farm in 2006. The entire experiment was repeated the following fruiting year in 2008. Within each of the five focal clones, five groups of five stems each were marked. Subsequently, all of the flowers on the terminal clusters of each of the stems within each focal clone were pollinated with pollen from one of the other clones or selfpollinated. Selfing rates were established for each pollen recipient but, as indicated previously, were not analyzed in the diallel. Approximately 25 flowers (among five stems) located on terminal clusters were pollinated. Mature berries were harvested, counted, and weighed during the first week of August for both years of the experiment. Berries were frozen at $-20{ }^{\circ} \mathrm{C}$ for subsequent seed counts.

Pairwise touching-neighbor. In this study, conducted in 2007 at the Blueberry Hill and Columbia sites, 22 focal pollen recipients received three pollination treatments: 1) self; 2) near touching-neighbor donor; and 3) far donor. Like in the diallel, $\approx 25$ flowers per crossing treatment were pollinated. This design allowed the collection of a significant amount of yield data on a large number of clones $(n=22)$. Focal pollen recipients were selected on the basis of their yield performance under open pollination conditions using data collected in 2005 at both Blueberry Hill and Columbia (Bell, 2009). We chose the two highest, the two midlevel, and the two lowest percent fruit setters (from open pollinations) at Blueberry Hill and Columbia for a total of 12 primary pollen recipients. These 12 primary pollen recipients, together with one of their randomly selected touching-neighbors, resulted in 22 total focal recipients (one pair succumbed to disease and was excluded at Blueberry Hill), which each received the three pollen treatments mentioned previously: 1) self pollen; 2) touching near neighbor donor; and 3 ) far donor $(\approx 300 \mathrm{~m})$ within the same field. Far male donors were included under the supposition that clones farther away might be genetically less related and thus represent a more genetically distant outcross than the near donor. Thus, we conducted this experiment in 2007 with 10 and 12 touching pairs (22 total pairs) from Blueberry Hill and Columbia, respectively.

\section{Seed counts}

In 2006 and 2007, seeds from all berries were extracted and tallied by size class using a dissecting microscope. In 2008, seeds from a sample of 10 representative berries (Krebs and
Hancock, 1991) for each pollination treatment, when available for that cross, were extracted. Following Bell (1957), three classes of seeds, mature, aborted, and small, which are presumed to be unfertilized ovules (Nuortila et al., 2006), were extracted and tallied for each pollination treatment. Large, mature seeds (germinable) were generally dark and $\approx 1.5 \mathrm{~mm}$ or greater in size; aborted seeds were somewhat smaller, angular, pale and/or shrunken; whereas small seeds were generally less than $0.5 \mathrm{~mm}$ (unfertilized ovules $\approx 0.35 \mathrm{~mm}$ ).

\section{Leaf tissue collections, DNA extraction, and sequence tag-polymerase chain reaction analysis}

The procedure for genomic DNA extraction has been detailed elsewhere (Bell et al., 2008, 2009) as well as the creation of the EST libraries that were used for the design of the primers in this study (Rowland et al., 2003a, 2003c). PCR and gel electrophoresis conditions as well as the primer sequences used have also been previously presented (Bell et al., 2008; Rowland et al., 2003a, 2003c). All reactions were repeated at least twice and reproducible polymorphic bands ranging from $\approx 300$ to $2500 \mathrm{bp}$ were scored. All bands were scored as dominant markers [i.e., band present (1) or band absent (0)] for each locus scored.

\section{Genotyping and estimation of genetic relatedness}

Because it is unlikely that significant cross pollination occurs at the distance between Blueberry Hill and Columbia [ $\approx 12.5 \mathrm{~km}$; see Bell et al., (2009) for a description of spatial genetic structure], each set of clones from each field were separately screened and scored against their own set of polymorphic EST-PCR primer combinations. For the touchingneighbor design, Blueberry Hill clones were screened against 27 primers, which yielded 103 polymorphic bands (average 3.8 bands per primer). For the Columbia field, clones were screened against 28 primers resulting in 94 polymorphic bands (3.6 bands per primer). For the five clones used in the $5 \times 5$ diallel, a total of 31 primers generated 90 polymorphic bands (average 2.9 bands per primer).

Using the binary data matrix generated from Blueberry Hill, Columbia, and the diallel clones, pairwise genetic similarities were estimated through the DICE algorithm (Dice, 1945; Nei and Li, 1979) in the SIMQUAL module of NTSYS Version 2.2 (Sneath and Sokal, 1973). The DICE algorithm $(2 \mathrm{a} / 2 \mathrm{a}+\mathrm{b}+\mathrm{c})$ is a measure of the proportion of shared bands over total bands scored for a pair of genotypes. Genetic similarity (gSim) was $\arcsin$ (sqrt) transformed because this improved fit in statistical models predicting yield (Zar, 1999).

\section{Yield measurements from hand crosses}

For both hand cross designs, we measured three postpollination yield parameters, which are of prime importance to growers and have implications in terms of individual fitness. These were: 1) proportion fruit set [subsequently referred to as $\mathrm{pFs}$ (berries harvested/flowers pollinated)]; 2) the mean number of mature seeds per pollination [subsequently referred to as mMature (proportion fruit set times the mean number of mature seeds per berry)]; and 3) the mean berry weight per pollination [subsequently referred to as $\mathrm{mWgt}$ (proportion fruit set times the mean berry weight)] (Krebs and Hancock, 1991). All yield variables are reported and analyzed as the pooled means of five stems in each pollination treatment. Proportion fruit set was $\arcsin$ (sqrt) transformed (Zar, 1999). 
In addition, two other derived variables were calculated. These were: 1) an estimate of total ovules by clone calculated as the sum of large + aborted + small seed for that cross (Nuortila et al., 2002); and 2) the proportion of large and the proportion aborted seed. As described by Krebs and Hancock (1991), the proportion of mature seed is estimated as the mean number of mature seeds per pollination divided by the mean number of mature seeds plus the mean number of aborted seeds per pollination. Its biological inverse is the proportion of aborted seeds. Both of these derived variables were also $\arcsin$ (sqrt) transformed. Increased numbers of ovules (yield potential) are known to be positively correlated with yield (Nuortila et al., 2002), and also, increased numbers of mature seeds (decreased aborted seeds) per berry are known to be correlated with berry size (Aalders and Hall, 1961; Eaton, 1967).

Preliminary analysis revealed that yield was highly correlated with total seeds (i.e., total ovules). Because clones differ in their total ovule counts (Bell, 2009), we used total seed as a covariate for all least squares regression analyses when predicting yield (Nuortila et al., 2006). In all cases, its inclusion in the model increased the goodness of fit of the model by accounting for the variance in yield resulting from the differential reproductive seed potential or the initial numbers of ovules that varied by clone (Bell, 2009).

An estimate of the relative genetic load carried by an individual (clone) was calculated from measurements of self to outcross fertility ratios (Krebs and Hancock, 1991; Levin, 1984; Sorensen, 1969). For a noninbred, autotetraploid: (2B) = $-12 \ln \left(\mathrm{S}_{\mathrm{S}} / \mathrm{S}_{\mathrm{o}}\right)$ in which $\mathrm{S}_{\mathrm{s}}$ and $\mathrm{S}_{\mathrm{o}}$ are derived from the proportion mature seed per pollination as given previously for self and outcross means, respectively. The concealed load per gamete is given by B, and thus, (2B) represents the number of lethal equivalents per zygote (Frankham et al., 2002; Morton et al., 1956). This parameter was calculated for focal pollen recipients (17 of 22) in the pairwise study and from the diallel clones that set fruit (four of five), yielding a total of 21 clones (Krebs and Hancock, 1991).

\section{Results}

We first present a summary of yield through a survey of the selfing rates of all 27 clones used in this 3-year study (both crossing designs pooled). Then, we present estimates of individual genetic load through an analysis that incorporates selfing and outcrossing rates (both crossing designs). We conclude with our analysis of yield as a function of genetic similarity (from marker data) and present the combining abilities as estimated from the diallel analysis.

Self FRUit SeT AND Genetic LOAD. Figure 1 shows the distribution of the proportion fruit set derived from the pooled self pollinations of all 27 clones used in our 3-year study (22 from the pairwise touching-neighbor study; five from the diallel). Fruit set of $0 \%$ to $10 \%$ was observed for 12 of the 27 clones (44\%). Nine clones (33\%) ranged from $10 \%$ to $40 \%$, and six $(22 \%)$ produced above $40 \%$ self fruit set. Thus, more than half $[15$ of $27(55 \%)$ ] of the clones produced greater than a $10 \%$ level of self fruit set. Three clones exhibited greater than $50 \%$ levels of self fruit set. A log normal distribution explains the observed self fruit set with a mean $( \pm \mathrm{SD})$ of $19.6 \% \pm 2.1 \%$ (Kolmogorov's $D=0.13, P=0.15$ ).

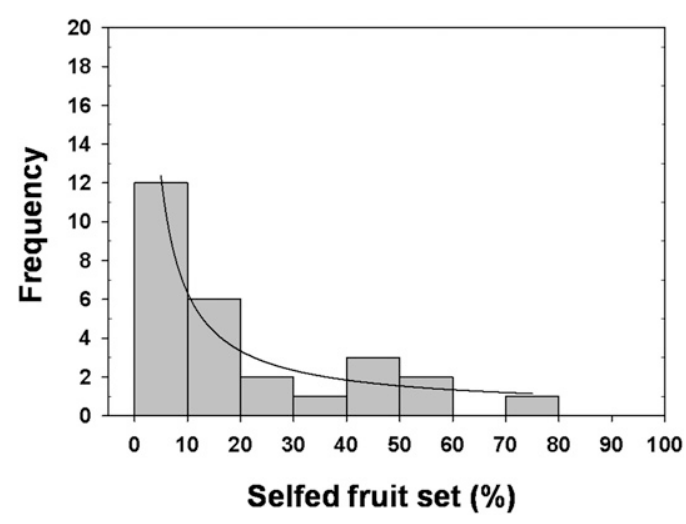

Fig. 1. Histogram showing distribution of percent self fruit set of 27 lowbush blueberry clones used as pollen recipients in this study. Six of 27 clones (22\%) showed greater than $40 \%$ self fruit set. The distribution follows a log normal distribution (Kolmogorov's $D=0.13, P=0.15$ ).

The self to outcross fertility results and the estimated number of lethal equivalents per zygote, i.e., genetic load (2B), among the 17 (17 of 22) clones from the 2007 pairwise touching-neighbor study and the 4 (four of five) clones from the 2006-2008 diallel study that set fruit are summarized in Table 1. Self $(\mathrm{S})$ versus outcross $(\mathrm{O})$ tests of mean fruit set, mean mature seed, and proportion mature seed showed that selffertility was lower than outcross fertility in all three cases. The 21 clones exhibited a wide range in both selfing and outcross fertility. For example, proportion fruit set ranged from $2 \%$ to $78 \%$ for self-pollinated clones and from $9 \%$ to $71 \%$ in outcrosses. A similar trend in pronounced range was also seen in mean mature seed and proportion mature seed. The number of lethal equivalents was best correlated with the self-fertility yield parameters, particularly the proportion self fruit set $(r=$ -0.77 self fruit, $P \leq 0.01)$. Outcross yield estimates were not found to be significantly correlated with estimates of lethal equivalents (2B). Outcross estimates were calculated from only two outcrosses in the pairwise study and four outcrosses in the diallel study. The highly variable self-fertility estimates drive the majority of variation in both the magnitude and range of lethal equivalents (mean $=20.2$, range $=0$ to 39.3).

We also compared overall yield of outcrossed clones with the same clones that were self-pollinated using mean number of mature seeds per pollination. This derived variable, calculated by multiplying proportion fruit set by the mean number of mature seeds for that pollination treatment, is, as a single index, highly informative of the productivity of a given crossing treatment. Using total seed number as a covariate for all 27 pollen recipients used in all 3 years of the experiments, the mean number of mature seeds per pollination for outcrosses was significantly greater than for selfing treatments $[16.5 \pm 0.9$ and $11.5 \pm 1.5$ (mean $\pm \mathrm{SD}$ ), respectively, $P=0.01]$. The mean number of aborted seeds per pollination was $18.9 \pm 0.8$ for outcross versus $21.9 \pm 1.4$ for self-pollination treatments $(P=0.07)$. In general, the numbers of aborted seeds did not change as dramatically as the numbers of mature seeds in self to outcross comparisons; however, the proportion of mature seeds for outcross and selfed treatments decreased significantly from 0.73 to $0.59(P<0.001)$, respectively, whereas the proportion of aborted seeds increased from 0.84 to 0.98 $(P<0.001)$. 
Table 1. Comparison of genetic loads for the pairwise and diallel lowbush blueberry clones used in this study ( $\mathrm{n}=21 ; 27$ minus 6 clones that set no fruit) as estimated by the comparison of the number of lethal equivalents per zygote $\left[-12 \ln (\mathrm{R})\right.$ where $\mathrm{R}=\mathrm{S}_{\mathrm{s}} / \mathrm{S}_{\mathrm{o}}$ and $\mathrm{S}_{\mathrm{s}}$ is the self mature seed (proportion) and $\mathrm{S}_{\mathrm{o}}$ is the outcrossed mature seed (proportion)] with mean fruit set for selfs (proportion), mean fruit set for outcrossers (proportion), mean mature seed for selfs, mean mature seed for outcrossers, proportion self mature seed, proportion outcrossed mature seed, relative survivorship, and lethal equivalents per zygote.

\begin{tabular}{|c|c|c|c|c|c|c|c|c|}
\hline $\begin{array}{l}\text { Pollen } \\
\text { recipient }\end{array}$ & $\begin{array}{l}\text { Mean fruit set } \\
\text { for selfs } \\
\text { (proportion) }\end{array}$ & $\begin{array}{l}\text { Mean fruit set } \\
\text { for outcrossers } \\
\text { (proportion) }\end{array}$ & $\begin{array}{c}\text { Mean mature } \\
\text { seed for } \\
\text { selfs }\end{array}$ & $\begin{array}{c}\text { Mean mature } \\
\text { seed for } \\
\text { outcrossers }\end{array}$ & $\begin{array}{l}\text { Self mature } \\
\text { seed } \\
\text { (proportion) }\end{array}$ & $\begin{array}{l}\text { Outcrossed } \\
\text { mature seed } \\
\text { (proportion) }\end{array}$ & $\begin{array}{c}\text { Relative } \\
\text { survivorship }\end{array}$ & $\begin{array}{c}\text { Lethal } \\
\text { equivalents } \\
\text { per zygote (no.) })^{\mathrm{z}}\end{array}$ \\
\hline $13+$ & 0.02 & 0.45 & 0.3 & 11.1 & 0.01 & 0.23 & 0.04 & 39.2 \\
\hline 6 & 0.03 & 0.35 & 0.3 & 6.7 & 0.01 & 0.13 & 0.06 & 34.5 \\
\hline 4 & 0.04 & 0.22 & 0.4 & 3.8 & 0.01 & 0.08 & 0.11 & 26.9 \\
\hline 2 & 0.05 & 0.37 & 0.2 & 6.7 & 0.01 & 0.21 & 0.05 & 36.8 \\
\hline $5 d$ & 0.09 & 0.51 & 0.1 & 10.1 & 0.01 & 0.23 & 0.04 & 39.3 \\
\hline $17+$ & 0.10 & 0.39 & 0.5 & 1.6 & 0.03 & 0.11 & 0.26 & 15.9 \\
\hline 11 & 0.13 & 0.37 & 0.8 & 3.8 & 0.02 & 0.10 & 0.20 & 19.1 \\
\hline $8+$ & 0.17 & 0.37 & 0.9 & 6.6 & 0.04 & 0.18 & 0.24 & 17.2 \\
\hline 8 & 0.17 & 0.27 & 3.1 & 7.3 & 0.06 & 0.13 & 0.47 & 9.0 \\
\hline $15+$ & 0.51 & 0.63 & 5.2 & 14.4 & 0.10 & 0.26 & 0.39 & 11.3 \\
\hline $1 \mathrm{~d}$ & 0.53 & 0.49 & 9.4 & 9.9 & 0.23 & 0.26 & 0.87 & 1.7 \\
\hline $8 \mathrm{C}$ & 0.54 & 0.71 & 2.7 & 13.4 & 0.07 & 0.28 & 0.24 & 17.2 \\
\hline $4 d$ & 0.65 & 0.56 & 12.9 & 12.6 & 0.26 & 0.25 & 1.04 & $\approx 0.0$ \\
\hline $2+$ & 0.78 & 0.67 & 21.3 & 14.6 & 0.44 & 0.34 & 1.31 & $\approx 0.0$ \\
\hline Mean & 0.25 & 0.42 & 3.9 & 8.0 & 0.09 & 0.19 & 0.41 & 20.2 \\
\hline Range & $0.02-0.78$ & $0.09-0.71$ & $0.07-21.3$ & $0.43-14.65$ & $0.01-0.44$ & $0.03-0.34$ & $0.04-1.31$ & $0.0-39.3$ \\
\hline $\begin{array}{l}\text { Correlation } \\
\text { with lethal } \\
\text { equivalents } \\
\text { per zygote }(r)\end{array}$ & $-0.77 * * x$ & $-0.29 \mathrm{NS}$ & $-0.76^{* *}$ & $-0.31 \mathrm{NS}$ & $-0.80 * *$ & $-0.30 \mathrm{NS}$ & N/A & N/A \\
\hline
\end{tabular}

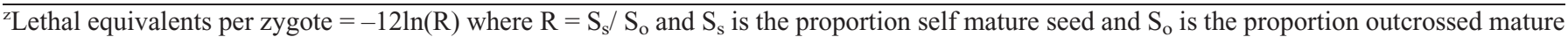
seed.

y " $d$ " clones denote the four clones used from the diallel as opposed to the pairwise study (shaded rows).

x**Significant at $P \leq 0.01$; NS $=$ nonsignificant.

$\mathrm{N} / \mathrm{A}=$ not applicable.

Proportion SELF FRUIT SET PREDicts outcross yield (GENERAL MODEL). Least squares modeling of the three transformed yield parameters resulting from outcrosses versus the transformed proportion self fruit set of all 27 clones are shown in Figure 2. A best fit for proportion self fruit set versus outcross yield was obtained by using the square (total seed) as a covariate (Figs. 2B, 2D, and 2F). For all three yield parameters, highly significant positive relationships were found between the proportion self fruit set of the pollen recipients and the same clone's outcrossing yields. Thus, self-fertility was positively correlated with outcross yield.

YIELD VERSUS GENETIC SIMILARITY - OVERALL. Least squares linear regression analysis depicting the three yield variables, transformed proportion fruit set ( $\left.\mathrm{t} \_\mathrm{pFs}\right)$, transformed mean number of mature seeds per pollination ( $\mathrm{t}$-mLarge), and transformed mean weight of berries per pollination (t_mWgt), as a function of transformed genetic similarity, are shown in Figure 3. Figures $3 \mathrm{~A}, 3 \mathrm{C}$, and $3 \mathrm{E}$ represent pooled self and outcrosses for all 3 years using 27 focal females $(n=91$ total crosses). Figures 3B, 3D, and 3F exclude the 27 self-treatments and represent 64 outcross pollinations. With self-pollinations included (Figs. 3A, 3C, and 3E), there was a significant negative slope in the relationship of the three yield parameters versus genetic similarity $(P=0.007,0.037$, and 0.033 , respectively). However, when excluding self-pollinations (Figs. $3 \mathrm{~B}, 3 \mathrm{D}$, and $3 \mathrm{~F}$ ), a nonsignificant relationship was found between yield and genetic similarity $(P=0.324,0.185$, and 0.076 , respectively). Thus, for outcrosses, increasing genetic similarity in the range measured among the clones chosen for this multiyear study did not result in the hypothesized decreased yields. The $r^{2}$ values for all comparisons were modestly high, ranging from 0.33 to 0.49 .

NEAR/FAR GENETIC SIMILARITY AND YIELD COMPARISONS. The mean genetic similarity between near breeding partners and far breeding partners in the touching-neighbor study (Table 2) was found to be not significantly different $[0.521 \pm 0.02$ and $0.505 \pm$ 0.07 (mean $\pm \mathrm{SD}$ ) for near and far male donors, respectively]. Proportion fruit set in crosses with near partners versus far partners was also not significantly different $(0.48 \pm 0.05$ and $0.51 \pm 0.21$ for near and far partners, respectively). However, 

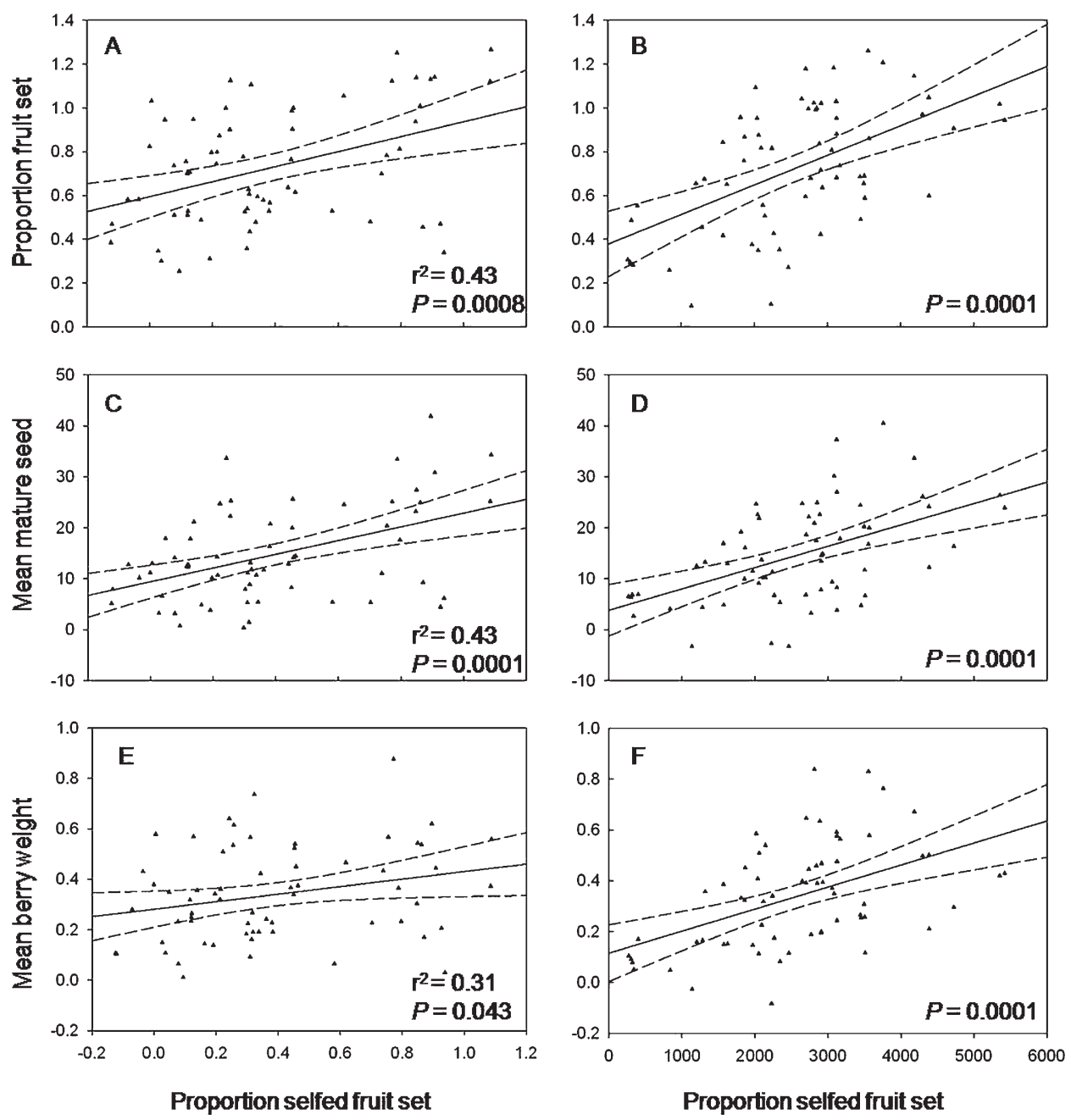

Fig. 2. Leverage plots (A, C, E) showing the response of the three yield variables, proportion fruit set, mean mature seed/pollination, and mean berry weight/pollination as a function of proportion self fruit set of lowbush blueberry clones $(\mathrm{n}=64)$. $(\mathbf{B}, \mathbf{D}, \mathbf{F})$ The plot of the covariate, square (totalSeed). R-squared $\left(r^{2}\right)$, and probability values are shown. All variables are arcsin (sqrt) transformed. The dotted lines are the 5\% confidence intervals about the line of fit.

the range in genetic similarity and fruit set was large for both near and far partners. Thus, genetic similarity of pollen donors for a given pollen recipient was probably not related to physical distance between clones in the field. In only seven (Table 2) of 33 genetic pairs (11 near, 11 far, 11 reciprocal) was the genetic similarity value higher than the 0.600 level, which was found in our previous study to approach half-sib/full-sib levels of genetic relatedness (Bell et al., 2009).

Diallel analysis. The pooled analysis of variance for the $5 \times 5$ diallel showed highly significant mean square estimates $(P \leq 0.003)$ for all three of the yield traits (Table 3$)$. GCA was significant $(P \leq 0.05)$ for $\mathrm{pFs}$ and $\mathrm{mWgt}$ but was only marginally significant for mMature $(P \leq 0.1)$. SCA was highly significant for both $\mathrm{pFs}$ and mMature $(P \leq 0.01)$. GCA estimates were consistently larger in all cases than SCA estimates indicating a larger proportion of additive to dominance variation. Reciprocal combining ability was significant $(P \leq 0.05)$ only for $\mathrm{pFs}$ indicating that the direction of the cross influences this yield parameter. Narrow-sense heritability estimates were relatively high for yield traits at $0.58,0.46$, and 0.56 for $\mathrm{pFs}$, mMature, and $\mathrm{mWgt}$, respectively.
Significant differences between years for $\mathrm{pFs}$ and $\mathrm{mWgt}$ were not evident. Despite a significant overall year effect for mMature $(P \leq$ 0.01 ), further analysis using JMP (Version 7; SAS Institute) revealed that the rank order by cross and year did not change significantly.

In comparison with overall model effects, analysis of yield attributes in individual half-sibs revealed that clones 1,4 , and 5 exhibited significantly positive GCA estimates, whereas clones 2 and 3 were significantly negative (Table 4). For example, pFs estimates were $0.17,0.14$, and 0.22 $(P \leq 0.01)$ for clones 1,4 , and 5, respectively, and -0.36 and -0.17 $(P \leq 0.01)$ for clones 2 and 3 , respectively. All GCA yield parameter estimates were significant $(P \leq$ $0.05)$ except for $\mathrm{mWgt}$ for clone $1(P \leq 0.10)$. Clone 3 exhibited significant negative maternal effects for $\mathrm{pFs}$ and mMature at -0.17 $(P \leq 0.01)$ and $-3.08(P \leq 0.05)$, respectively. In contrast, clone 5 showed a small but significant positive maternal effect at $0.07(P \leq$ $0.05)$ for $\mathrm{pFs}$.

Because the GCA yield estimates for clones 2 and 3 were significantly negative (Table 4), specific crosses involving these clones generally produced negative SCA yield estimates (Table 5). This is particularly evident in crosses between clones 2 and 5 and clones 3 and 4. Crosses involving clones 4 and 5 exhibited the highest significant SCA among the crosses performed, indicating a synergistic effect in their SCA. For all three yield parameters, crosses between clones 4 and 5 resulted in a significant increase of $0.15(P \leq 0.01), 8.54$ $(P \leq 0.01)$, and $0.11(P \leq 0.05)$ in $\mathrm{pFs}$, mMature, and $\mathrm{mWgt}$, respectively. Positive SCA estimates for the cross between clones 2 and 3 are misleading. Clones 2 and 3 exhibit poor yield attributes as evidenced by their negative GCAs. These positive SCA values are actually an arithmetic anomaly resulting from how SCA is calculated by the subtraction of negative GCA values from the actual yield values thereby causing an increase in the SCA estimate (Griffing, 1956).

Although general model reciprocal effects were only significant in $\mathrm{pFs}$, there were two specific combinations of interest involving crosses between clones 1 and 3 and clones 3 and 5 (Table 5). Crosses between clones 1 and 3 revealed that the cross direction $1 \times 3$ ( 1 sired by 3$)$ performed better $[\mathrm{REC}=$ $0.21(P \leq 0.05)]$ than the reverse. Crosses between clones 3 and 5 performed worse $[\mathrm{REC}=-0.28 ;(P \leq 0.01)]$ in the $3 \times 5(3$ sired by 5$)$ direction than the opposite. Both of these directional reciprocal deviations were expected considering the relative GCA estimates of the cross participants (clones 1 and 5 have 

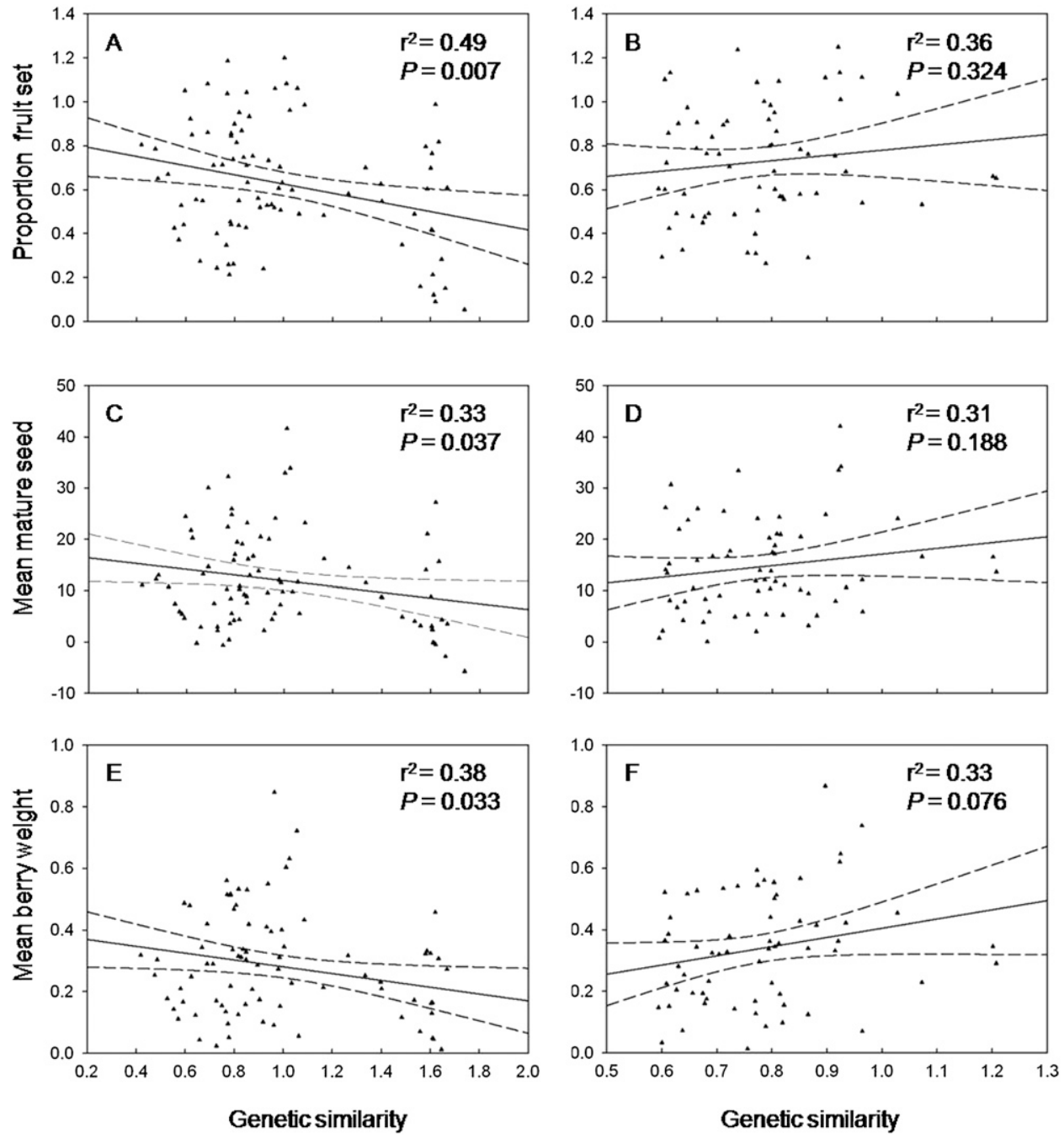

Fig. 3. Leverage plots showing modeling of the three yield variables, proportion fruit set (t_pFs), mean number of mature seeds per pollination (t_mMature), and mean berry weight per pollination ( $\mathrm{t} \_\mathrm{mWgt}$ ) versus genetic similarity in lowbush blueberry. (A, C, E) The relationship with self-crosses included at a relationship of one (n $=91$ crosses $)$. $(\mathbf{B}, \mathbf{D}, \mathbf{F})$ The same relationship but with the selfs excluded $(\mathrm{n}=64$ crosses $)$. All variables are $\arcsin ($ sqrt) transformed. The dotted lines are the 5\% confidence intervals about the line of fit.

significantly positive GCA estimates; clone 3, a significantly negative maternal GCA estimate).

\section{Discussion}

A pronounced range and rank stratification for yield among lowbush and highbush blueberry clones has been reported (Bell, 2009; Hepler and Yarborough, 1991; Vander Kloet and Cabilio, 1996). In the current study, a large range and a highly significant year-to-year correlation by clone was found for yield in proportion fruit initiation and set. Our results provide a genetic basis to account for how proximal clones (close neighbors within a field and thus within pollen exchange distance) that started the season with comparable numbers of flowers exhibit multifold differences in yield despite having set and developed fruit under conditions in which environmental variability (fertility, pest control, and pollinator density) has been minimized by rigorous cultivation practices. Our results suggest that: 1) a clone's yield is an inherent function of its own limiting maternal genetic makeup; and/or
2) yield is influenced by the pollen environment a clone happens to populate.

Bell et al. (2009) found through statistical analyses of the spatial genetic structure of four Maine blueberry fields that there is a random relationship between the genetic similarity and physical distance between clones at the within-field level. Our pairwise, touching-neighbor study corroborates these findings (Table 2). We found no significant difference in average genetic similarity between near neighbors $(0.521)$ as compared with far neighbors (0.505). A near neighbor was as genetically similar as 0.765 or as dissimilar as 0.308 . We also found no significant difference in yield as measured by mean proportion fruit set with near and far pollen donors (0.48 and 0.51).

Bell et al. (2008), using ESTPCR markers and one known pedigree of four clones, demonstrated that half-sib to full-sib partners in lowbush blueberry have genetic similarity values ranging from 0.643 to 0.800 . Using random amplified polymorphism DNA markers and the same similarity coefficient (Dice, 1945; Nei and Li, 1979), Burgher et al. (2002) found similar parentprogeny similarity values $(\approx 0.770)$. For our populations, genetic similarity rarely exceeded 0.600 between near neighbors [six of $22(27 \%)$ ]. At the within-field spatial scale, the majority of clones (64\%) were only moderately related with similarity values between 0.4 and 0.6 .

Our results (Fig. 3) document that yield variables in outcrosses did not significantly correlate with genetic similarity. Only by the inclusion of self crosses was a significant depression for yield found (negative slope). Thus, inbreeding depression was apparent only in the most extreme cases through selfing. Even when grouping the crosses into two classes of parents with genetic similarity values of $\geq 0.600$ and $<0.600$, significant inverse relationships between any of the yield variables and genetic similarity were not found.

Autotetraploids, particularly those displaying tetrasomic inheritance like lowbush blueberry does (Hokanson and Hancock, 1993), are known to be particularly resistant to fixation and therefore are more tolerant of the detrimental effects of near parental inbreeding depression that could result from mating genetically similar parent clones. Haldane (1930) noted that autotetraploids approach fixation on selfing at one-third the rate of diploids. Busbice (1968) showed that, when using the inbreeding depression susceptible autotetraploid alfalfa (Medicago sativa), a curvilinear decline in yield resulted as a result of the subsequent generational increase of the zygotic inbreeding 
Table 2. Genetic similarity (gSim) and fruit set (proportion) by near and far donors from the 2007 pairwise field hand crosses of lowbush blueberry clones $(\mathrm{n}=44$ total crosses).

\begin{tabular}{|c|c|c|c|c|}
\hline $\begin{array}{l}\text { Pollen } \\
\text { recipient }\end{array}$ & $\begin{array}{l}\text { Near donor } \\
\text { gSim }\end{array}$ & $\begin{array}{l}\text { Near donor fruit set } \\
\text { (proportion) }\end{array}$ & $\begin{array}{l}\text { Far donor } \\
\text { gSim }\end{array}$ & $\begin{array}{l}\text { Far donor fruit set } \\
\text { (proportion) }\end{array}$ \\
\hline 10 & 0.435 & 0.10 & 0.488 & 0.07 \\
\hline $10+$ & 0.491 & 0.20 & 0.488 & 0.11 \\
\hline $11+$ & 0.730 & 0.80 & 0.667 & 0.41 \\
\hline 13 & 0.623 & 0.56 & 0.508 & 0.76 \\
\hline $13+$ & 0.516 & 0.44 & 0.508 & 0.65 \\
\hline $15+$ & 0.606 & 0.87 & 0.559 & 0.62 \\
\hline 17 & 0.643 & 0.47 & 0.392 & 0.36 \\
\hline $17+$ & 0.311 & 0.37 & 0.392 & 0.57 \\
\hline 2 & 0.491 & 0.73 & 0.526 & 0.52 \\
\hline $2+$ & 0.452 & 0.90 & 0.526 & 0.80 \\
\hline 4 & 0.577 & 0.11 & 0.440 & 0.33 \\
\hline $6+$ & 0.377 & 0.49 & 0.520 & 0.57 \\
\hline 8 & 0.765 & 0.39 & 0.522 & 0.42 \\
\hline $8+$ & 0.523 & 0.60 & 0.522 & 0.29 \\
\hline $8+C$ & 0.500 & 0.72 & 0.509 & 0.54 \\
\hline $8 \mathrm{C}$ & 0.627 & 0.96 & 0.509 & 0.62 \\
\hline Mean \pm SD & $0.521 \mathrm{a}^{\mathrm{z}} \pm 0.02$ & $0.48 \mathrm{a} \pm 0.05$ & $0.505 \mathrm{a} \pm 0.07$ & $0.51 \mathrm{a} \pm 0.21$ \\
\hline Range & $0.308-0.765$ & $0.03-0.96$ & $0.392-0.667$ & $0.07-0.90$ \\
\hline
\end{tabular}

${ }^{\mathrm{z}}$ Genetic similarity and proportion fruit set comparisons that share the same letter are not significantly different.

Table 3. Pooled analyses of variance for a $5 \times 5$ diallel performed as a Griffing's Diallel Model 2 (random), Method 3 (F1s and reciprocals, no selfs) conducted on five randomly chosen lowbush blueberry clones from the Blueberry Hill. ${ }^{z}$

\begin{tabular}{lrccc}
\hline \multirow{2}{*}{$\begin{array}{l}\text { Source of } \\
\text { variation }\end{array}$} & & \multicolumn{2}{c}{ Mean squares } \\
\cline { 3 - 5 } & $\mathrm{df}$ & $\begin{array}{c}\text { Proportion } \\
\text { fruit set }(\mathrm{pFs})\end{array}$ & $\begin{array}{c}\text { Mean mature seeds per } \\
\text { pollination (mMature) }\end{array}$ & $\begin{array}{c}\text { Mean berry wt per } \\
\text { pollination (mWgt) }\end{array}$ \\
\hline Years & 1 & 0.06 & $370.8^{* * x}$ & 0.001 \\
Crosses & 20 & $0.22^{* *}$ & $257.2^{* *}$ & $0.070^{* *}$ \\
GCA & 4 & $0.79^{* \mathrm{x}}$ & $827.1 \dagger^{\mathrm{x}}$ & $0.268^{*}$ \\
SCA & 5 & $0.11^{* *}$ & $185.2^{* *}$ & $0.047 \dagger$ \\
REC & 10 & $0.06^{*}$ & 53.9 & 0.009 \\
Error & 19 & 0.02 & 36.4 & 0.019 \\
$\mathrm{~h}^{2} \mathrm{w}$ & & 0.58 & 0.46 & 0.56 \\
Trait mean & & 0.36 & 8.5 & 0.17 \\
$r^{2 \mathrm{v}}$ & & 91.0 & 8.2 & 79.3 \\
\hline
\end{tabular}

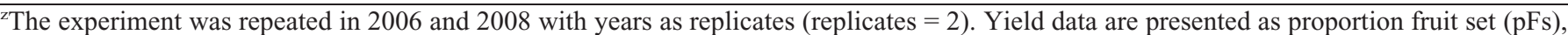
mean number of mature seeds per pollination (mMature), and mean berry weight per pollination $(\mathrm{mWgt})$. Narrow-sense heritability $\left[\mathrm{h}^{2}=\sigma^{2}{ }_{\mathrm{A}}{ }^{\prime}\right.$ $\left(\sigma_{\mathrm{A}}^{2}+\sigma_{\mathrm{D}}^{2}+\sigma_{\mathrm{e}}^{2} \mathrm{r}\right]$; in which $\sigma_{\mathrm{A}}^{2}=4 \sigma_{\mathrm{GCA}}^{2}-(2 / 3) \sigma_{\mathrm{SCA}}^{2}, \sigma_{\mathrm{D}}^{2}=6 \sigma_{\mathrm{SCA}}^{2}, \sigma_{\mathrm{e}}^{2}=$ model error, and $\mathrm{r}=$ replications $)$ corrected for an autotetraploid (Ortiz and Golmirzaie 2002) is also reported along with trait means and $r^{2}$ ("goodness of fit").

${ }^{\mathrm{y}} \mathrm{GCA}=$ general combining ability; SCA $=$ specific combining ability; REC = reciprocal.

$\mathrm{x} \uparrow, *, * *$ Significant at $10 \%, 5 \%$, and $1 \%$ probability levels, respectively.

"Narrow-sense heritability.

${ }^{\mathrm{v}}$ Goodness of fit [i.e., the proportion of the entire model variability that the treatment affect (crosses) explains].

coefficient of the progeny. However, this decrease resulted only by the experimental creation of two tiers of selfed populations (i.e., extreme inbreeding). Highbush blueberry is an autotetraploid relative of lowbush blueberry and also exhibits inbreeding depression. Krebs and Hancock (1990) concluded from yield measurements in crossing experiments using four cultivars of known pedigree that crosses approximating half-sib to full-sib relationships yielded responses that were "...too low to result in a detectable fertility response...." Similar to our results, an effect of genetic relatedness on yield was evident only when self pollinations were included in the analysis. This same phenomenon has been reported for 
Table 4. Individual general combining ability (GCA) and maternal effects (MAT) for three yield traits measured: proportion fruit set (pFs), mean mature seeds per pollination (mMature), and mean berry weight per pollination ( $\mathrm{mWgt}$ ) in a $5 \times 5$ diallel (Griffing's Diallel Model 2, Method 3) with five randomly chosen lowbush blueberry clones from Blueberry Hill Farm, Jonesboro, ME.

\begin{tabular}{|c|c|c|c|c|c|c|}
\hline \multirow{2}{*}{$\begin{array}{l}\text { Trait } \\
\text { Clone }\end{array}$} & \multicolumn{2}{|c|}{ Proportion fruit set (pFs) } & \multicolumn{2}{|c|}{ Mean mature seeds (mMature) } & \multicolumn{2}{|c|}{ Mean berry wt (mWgt) } \\
\hline & GCA & MAT & GCA & MAT & GCA & MAT \\
\hline 1 & $0.17 * * \mathrm{z}$ & -0.12 & $4.5^{* z}$ & -0.42 & $0.07 \dagger^{z}$ & -0.007 \\
\hline 2 & $-0.36^{* *}$ & 0.007 & $-11.1 * *$ & 0.10 & $-0.20 * *$ & 0.002 \\
\hline 4 & $0.14 * *$ & 0.05 & $5.8^{* *}$ & 1.42 & $0.09 *$ & 0.009 \\
\hline 5 & $0.22 * *$ & $0.07 *$ & $7.4 * *$ & 1.98 & $0.15^{* *}$ & 0.037 \\
\hline
\end{tabular}

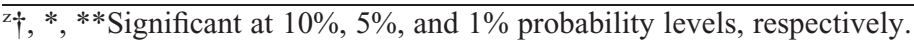

Table 5. Specific combining ability (SCA) and reciprocal (REC) effects for a $5 \times 5$ diallel (Griffing's Diallel Model 2, Method 3) of the three yield attributes of proportion fruit set $(\mathrm{pFs})$, mean mature seeds per pollination (mMature), and mean berry weight per pollination (pWgt) with five randomly chosen lowbush blueberry clones from Blueberry Hill Farm, Jonesboro, ME.

\begin{tabular}{|c|c|c|c|c|c|}
\hline Statistic/trait & Clone & 2 & 3 & 4 & 5 \\
\hline $\mathrm{SCA} /(\mathrm{pFs})$ & \multirow[t]{6}{*}{1} & -0.03 & -0.03 & $0.13^{* z}$ & -0.07 \\
\hline REC & & $(-0.08)^{y}$ & $(0.21 *)$ & $(-0.08)$ & $(-0.11)$ \\
\hline $\mathrm{SCA} /(\mathrm{mMature})$ & & -0.04 & 0.27 & 1.69 & -1.92 \\
\hline $\mathrm{REC}$ & & $(-1.61)$ & $\left(6.58 \dagger^{z}\right)$ & $(-3.27)$ & $(-3.77)$ \\
\hline $\mathrm{SCA} /(\mathrm{mWgt})$ & & -0.005 & -0.04 & 0.03 & $-0.02 *$ \\
\hline REC & & $(-0.01)$ & $(0.04)$ & $(0.002)$ & $(-0.07)$ \\
\hline $\mathrm{SCA} /(\mathrm{pFs})$ & \multirow[t]{6}{*}{2} & & $0.21 * * z$ & -0.08 & $-0.10 \dagger$ \\
\hline REC & & & $(-0.18)$ & $(-0.05)$ & $(0.03)$ \\
\hline $\mathrm{SCA} /(\mathrm{mMature})$ & & & $8.31 * *$ & -3.57 & $-4.70 \dagger$ \\
\hline REC & & & $(-0.08)$ & $(-0.47)$ & $(-0.57)$ \\
\hline $\mathrm{SCA} /(\mathrm{mWgt})$ & & & $0.16^{* *}$ & -0.05 & $-0.10 *$ \\
\hline REC & & & $(0.002)$ & $(-0.005)$ & $(0.007)$ \\
\hline $\mathrm{SCA} /(\mathrm{pFs})$ & \multirow[t]{6}{*}{3} & & & $-0.20 * *$ & 0.02 \\
\hline REC & & & & $(-0.10)$ & $(-0.28 * *)$ \\
\hline $\mathrm{SCA} /(\mathrm{mMature})$ & & & & $-6.66^{*}$ & -1.92 \\
\hline $\mathrm{REC}$ & & & & $(-1.32)$ & $(-7.60 *)$ \\
\hline $\mathrm{SCA} /(\mathrm{mWgt})$ & & & & $-0.09 \dagger$ & -0.03 \\
\hline REC & & & & $(-0.05)$ & $(-0.10 \dagger)$ \\
\hline $\mathrm{SCA} /(\mathrm{pFs})$ & \multirow[t]{6}{*}{4} & & & & $0.15^{* *}$ \\
\hline REC & & & & & $(0.03)$ \\
\hline $\mathrm{SCA} /(\mathrm{mMature})$ & & & & & $8.54 * *$ \\
\hline REC & & & & & $(2.01)$ \\
\hline $\mathrm{SCA} /(\mathrm{mWgt})$ & & & & & $0.11 *$ \\
\hline REC & & & & & $(-0.01)$ \\
\hline
\end{tabular}

$\mathrm{z}_{\dagger}, *$, **Significant at $10 \%, 5 \%$, and $1 \%$ probability levels, respectively.

rabbiteye blueberry (Hellman and Moore, 1983; Lyrene, 1983).

In a recent study of another outcrossing tetraploid, Ranunculus reptans, Willi and Van Buskirk (2005) found that genomic compatibility, as measured by relative yield, spans a wide range of parental similarity. Calculated by allozymes, only at genetic similarity values greater than 0.8 did progeny performance begin to decline. Albeit, our genetic similarity estimates may not be entirely comparable with theirs because they were estimated by different methods, in $R$. reptans at the range of genetic similarities between 0.4 and 0.6 , progeny yield performance was flat, i.e., tolerant in these midranges of parental similarity. These results, in an outcrossing species, are congruent with ours. In our study, neither naturally produced field genetic structure nor artificially comparing genetically close crosses to far supported the hypothesis of Myra et al. (2004) that clusters of genetically similar neighbors are responsible for lowbush blueberry yield depression within fields.

An early report of self-sterility in lowbush blueberry (Aalders and Hall, 1961) suggested that the species is nearly entirely self-infertile. Under greenhouse conditions, their study reported that 12 of $21(57.1 \%)$ clones failed to set self fruit and that only two of $21(9.5 \%)$ clones were greater than $40 \%$ selffertile. In a well-managed field environment, our study (Fig. 1) demonstrated that only five of $27(18.5 \%)$ clones did not set self fruit and six of $27(22.2 \%)$ were greater than $40 \%$ self-fertile. In agreement with our findings, using a considerably larger sample size in an open pollinated field environment, Wood (1968) also found lower levels of self-sterility [five of 92 clones (5.4\%)] and greater than $50 \%$ self-fertility in $48 \%$ of the tested clones. Wood (1968) was the first researcher, to our knowledge in lowbush blueberry, to demonstrate not only that lowbush was more self-fertile than thought, but also that self-fertility and outcross yield were correlated.

Variation observed in self-fertility estimates were the primary determinants of the range in lethal equivalents (genetic load) observed among 21 clones used in this study (Table 1). Sorensen's (1969) adaptation of Morton et al.'s (1956) concept of exposing hidden lethal equivalents through the ratio of self to outcross fertility was based on the idea that the genetic load carried by members of a population could be derived by comparison of the self to outcross ratio from experimental hand pollinations. Two key points of evidence for the contribution of post-zygotic inbreeding depression to self-infertility versus the alternative possibility of prezygotic self-incompatibility are: 1 ) differential self-fertility of individuals in a population; and 2) temporal production of aborted seed, i.e., aborted seeds of different sizes suggesting abortion at different times during their development. The latter is attributed to differential genetic load in newly formed zygotes causing staggered abortions over time (Seavy and Bawa, 1986). Our results, demonstrating the range in selfing rates and the variable range in size of collapsed, aborted seeds, provides evidence for both of these phenomena in lowbush blueberry.

A series of reports focusing on highbush blueberry (one of which also included lowbush blueberry) used a variety of measures for fertility and concluded that early-acting embryonic inbreeding depression is the principal cause of selfinfertility (Hokanson and Hancock, 2000; Krebs and Hancock, 
1988, 1990, 1991). Although caution should be exercised in comparing values derived from different measures of self and outcross fitness from different taxa (Sorensen, 1969), Krebs and Hancock's (1991) estimate of genetic load (mean of 9.6 lethal equivalents) was as high as that reported in gymnosperms (Franklin, 1972; Park and Fowler, 1982; Sorensen, 1969). Hokanson and Hancock (2000) reported a significant correlation between self and outcross fertility in $V$. corymbosum and $V$. myrtilloides, but could not demonstrate this same phenomenon in $V$. angustifolium.

Among the three measures of yield (Table 1), we found the highest correlation between the proportion self fruit set attribute and genetic load $(r=-0.77, P \leq 0.01)$. A comparison of previous reports suggests that lowbush blueberry is considerably less self-fertile than highbush blueberry. Consistent with these observations, our estimate of genetic load (average number of lethal equivalents) in lowbush blueberry of 20.2 is considerably higher than that in highbush blueberry of 9.6. Our three pairwise self and outcross estimates for mean fruit set, mean mature seed, and proportion mature seed were highly correlated $(r=0.77, P \leq 0.01 ; r=0.65, P \leq 0.01$; and $r=0.65$, $P \leq 0.01$, respectively). Thus, as self-fertility increases, so too does outcross yield. The goodness of fit for this relationship is moderately high for hand crosses conducted under field conditions. We interpret such correlations between self and outcross yields as evidence for a common type of control, namely genetic load, operating under both self and outcross conditions. This association has been postulated by Hokanson and Hancock (2000) for autotetraploid highbush blueberry and by Busbice (1968) for autotetraploid alfalfa.

Our observations in lowbush blueberry strongly suggest that this species harbors a markedly high genetic load and that this load is at least correlated with and may even be causally associated with a significant component of yield in crosses between clones. We have shown that clones exhibit a range in lethal equivalents from near 0 to 39.3, which supports our previous studies (Bell et al., 2009) showing a great amount of genetic variation present in the species. The species tolerance and accumulation of high genetic load may be conditioned by its extreme longevity ( $\approx 200$ years) and its clonal habit (Klekowski, 1988; Klekowski and Godfrey, 1989).

Although we were not attempting to track a complex, quantitatively inherited trait such as yield through several generations, it became apparent that a simple analysis of variance did not provide sufficient discriminatory statistical power in separating variance components involved in a diallel crossing experiment. Lipow and Wyatt (1999) used a full diallel to partition the variance components of three post-pollination processes, including fruit set, seed number, and mass in milkweed, Asclepias incarnata. Using the "biomodel" of Cockerham and Weir (1977) and other well-known statistical approaches such as Griffing's (1956) analyses for diallels, variance components can be estimated that include not only parental effects, but also GCA and SCA. Using Griffing's Model 2, Method 3, we were able to partition several informative variance components. The most important finding was the preponderance of additive genetic actions (GCA) over dominance interactions (SCA). GCA accounted for $\approx 50 \%$ of the total model variability and SCA for $\approx 20 \%$ with the balance being apportioned to reciprocal $(10 \%)$ and error $(20 \%)$. This relative proportion was similar for all three yield traits and translated to a moderately high narrow-sense heritability for all three yield traits, proportion fruit set, mean number of large seeds per pollination, and mean berry weight per pollination $\left(\mathrm{h}^{2}\right.$ $=0.58,0.46$, and 0.56 , respectively). This finding has applied value because by screening clones for good selfed fruit set or related yield attributes, it should be possible to regain in cross performance the additive GCA component for parental yield.

Among the five random clones entered into our diallel, clones 2 and 3 showed little promise based on significantly negative individual GCA estimates, whereas clones 1, 4, and 5 exhibited significantly positive GCA estimates and offer promising opportunities for further breeding. Self fruit set explained a moderate amount of the variation in outcross yield measures ( $r^{2} \approx 0.43$; Fig. 2$)$. Some of the unexplained variance might be attributed to sampling error related to the inherent difficulties in field hand crosses. The remainder may be explained by variation in SCA, which is defined as the deviation of actual yield of a cross from that projected as a result of the mutual parental GCAs (Griffing, 1956; Hallauer and Miranda, 1988). In other words, directional dominance interactions and other more complex genetic effects such as epistasis can unpredictably influence yield. Breeders have long recognized that SCA in diallel crosses is difficult to predict (Griffing, 1956; Hallauer and Miranda, 1988; Hayman, 1954). We have demonstrated significant positive (clones 4 and 5) and negative (clones 3 and 4) SCA effects in hybrid crosses. Thus, some of the residual error is attributed to individual crosses that deviate from model predictions based on GCA.

\section{Summary}

We have demonstrated that: 1) lowbush blueberry clone yield is influenced by its own genetic makeup; and 2) yield is affected by the pollen environment a clone is situated in. Using molecular genotyping tools and the estimates of genetic similarity they can provide, together with observations on the diversification and stratification of yield, under conditions in which outcrossing predominates, the degree of genetic similarity between different potential parents within the same field does not have marked influence on yield. Inclusion of selfpollination, however, has a negative effect on yield. From the perspective of the reproductive biology of lowbush blueberry, this point is highly germane. Bee foraging patterns (Aras et al., 1996; Wood, 1968; F.A. Drummond, unpublished data) suggest that self-pollination must be occurring in fields and must thus impact yield differentials among clones. Modeling local gene flow by pollen and estimating levels of self and outcross pollen deposition using these newly developed molecular markers is currently being undertaken in our laboratory. We have established from field hand crosses that self-fertility is a significant predictor of outcross yield. The less than perfect fit, or residual error of the self to outcross model, which accounted for over half of the total model variability, must in part be attributable to SCA effects in cross participants, in which yield can depart significantly from predictions based on the parental genetic loads and/or their GCA. In conclusion, our evidence indicates that yield is driven by the inherent genetics of the pollen recipient (relative genetic load/GCA) and that of the pollen donor. The occurrence of directional dominance deviations (SCA) is consistent with a system harboring a high genetic load and susceptible to inbreeding depression.

Our results provide a rationale for a systematic approach in repopulating bare areas of lowbush blueberry fields or, perhaps, 
even populating new fields. Large-scale screening for clones with high levels of self-fertility could be followed by their inclusion in hybrid crosses to identify high-yielding parental combinations. Inclusion of parental lines with high combining ability in heterogeneous populations or family-based approaches as demonstrated by Jamieson (2008a, 2008b) could result in a large number of productive hybrid seed families that could be deployed into fields in Maine. If the scope were aggressive enough, these seed families would be many in number and would not diminish the valuable genetic heterogeneity that is currently present and likely necessary to limit inbreeding depression in the species.

\section{Literature Cited}

Aalders, L.E. and I.V. Hall. 1961. Pollen incompatibility and fruit set in lowbush blueberries. Can. J. Genet. Cytol. 3:300-307.

Aras, P., D. de Oliveira, and L. Savoie. 1996. Effect of a honeybee (Hymenoptera: Apidae) gradient on the pollination and yield of lowbush blueberry. J. Econ. Entomol. 89:1080-1083.

Bell, D.J. 2009. Spatial and genetic factors influencing yield in lowbush blueberry (Vaccinium angustifolium) in Maine. PhD Diss., Univ. of Maine, School of Biological Sciences, Orono, ME.

Bell, D.J., L.J. Rowland, J.J. Polashock, and F.A. Drummond. 2008. Suitability of EST-PCR markers developed in highbush blueberry for genetic fingerprinting and relationship studies in lowbush blueberry and related species. J. Amer. Soc. Hort. Sci. 133:701-707.

Bell, D.J., L.J. Rowland, D. Zhang, and F.A. Drummond. 2009. The spatial genetic structure of lowbush blueberry, Vaccinium angustifolium, in four fields in Maine. Botany 87:932-946.

Bell, H.P. 1957. The development of the blueberry seed. Can. J. Bot. 35:139-153.

Burgher, K.L., A.R. Jamieson, and X. Lu. 2002. Genetic relationships among lowbush blueberry genotypes as determined by randomly amplified polymorphic DNA analysis. J. Amer. Soc. Hort. Sci. 127:98-103.

Busbice, T.H. 1968. Effects of inbreeding on fertility in Medicago sativa. Crop Sci. 8:231-234.

Cockerham, C.C. and B.S. Weir. 1977. Quadratic analyses of reciprocal crosses. Biometrics 33:187-203.

Cho, E., J.M. Seddon, B. Rosner, W.C. Willett, and S.E. Hankinson. 2004. Prospective study of intake of fruits, vegetables, vitamins, and carotenoids and risk of age-related maculopathy. Arch. Ophthalmol. 122:883-892.

Dice, L.R. 1945. Measures of the amount of ecological association between species. Ecology 26:297-302.

Drummond, F.A. 2000. History of insect pest management for lowbush blueberries in Maine. Trends Entomol. 3:23-32.

Drummond, F.A. 2002. Honeybees and blueberry pollination. University of Maine, Wild Blueberry Bul. No. 629.

Eaton, E.L. 1967. The relationship between seed number and berry weight in open pollinated highbush blueberries. HortScience 2:14-15.

Frankham, R., J.D. Ballou, and D.A. Brisco. 2002. Introduction to conservation genetics. Cambridge University Press, Cambridge, UK.

Franklin, E.C. 1972. Genetic load in loblolly pine. Amer. Nat. 106:262-265.

Griffing, B. 1956. Concept of general and specific combining ability in relation to diallel crossing systems. Aust. J. Biol. Sci. 9:463-493.

Haldane, J.B.S. 1930. Theoretical genetics of autopolyploids. J. Genet. 22:359-372.

Hall, I.V., L.E. Aalders, N.L. Nickerson, and S.P. Vander Kloet. 1979. The biological flora of Canada. 1. Vaccinium angustifolium, sweet lowbush blueberry. Can. Field-Naturalist 93:415-430.

Hallauer, A.R. and J.B. Miranda. 1988. Quantitative genetics in maize breeding. 2nd Ed. Iowa State University Press, Ames, IA.

Hayman, B.I. 1954. The theory and analysis of diallel crosses. Genetics 39:789-809.
Hellman, E.W. and J.N. Moore. 1983. Effect of genetic relationship to pollinizer on fruit, seed, and seedling parameters in highbush and rabbiteye blueberries. J. Amer. Soc. Hort. Sci. 108: 401-405.

Hepler, P.R. and D.E. Yarborough. 1991. Natural variability in yield of lowbush blueberry. HortScience 26:245-246.

Hokanson, K. and J. Hancock. 1993. The common lowbush blueberry, Vaccinium angustifolium, may be an autopolyploid. Can. J. Plant Sci. 73:889-891.

Hokanson, K. and J. Hancock. 2000. Early-acting inbreeding depression in three species of Vaccinium (Ericaceae). Sex. Plant Reprod. 13:145-150.

Jamieson, A.R. 2008a. Developing seed-propagated lowbush blueberry families. HortScience 43:1686-1689.

Jamieson, A.R. 2008b. 'Novablue', a seed-propagated lowbush blueberry family. HortScience 43:1902-1903.

Kalt, W., J.A. Joseph, and B. Shukitt-Hale. 2007. Blueberries and human health: A review of the current research. J. Amer. Pomol. Soc. 61:151-160.

Klekowski, E.J. 1988. Mutation, developmental selection, and plant evolution. Columbia University Press, New York, NY.

Klekowski, E.J. and P.J. Godfrey. 1989. Aging and mutation in plants. Nature 340:389-391.

Krebs, S.L. and J. Hancock. 1990. Early-acting inbreeding depression and reproductive success in the highbush blueberry, Vaccinium corymbosum L. Theor. Appl. Genet. 79:825-832.

Krebs, S.L. and J.F. Hancock. 1988. The consequences of inbreeding on fertility in Vaccinium corymbosum L. J. Amer. Soc. Hort. Sci. 113:914-918.

Krebs, S.L. and J.F. Hancock. 1991. Embryonic genetic load in the highbush blueberry, Vaccinium corymbosum (Ericaceae). Amer. J. Bot. 78:1427-1437.

Levin, D.A. 1984. Inbreeding depression and proximity-dependent crossing success in Phlox drummondii. Evolution 38:116-127.

Lipow, S.R. and R. Wyatt. 1999. Diallel crosses reveal patterns of variation in fruit-set, seed mass, and seed number in Asclepias incarnata. Heredity 83:310-318.

Lyrene, P.M. 1983. Inbreeding depression in rabbiteye blueberries. HortScience 18:226-227.

Morton, N.E., J.F. Crow, and H.J. Muller. 1956. An estimate of mutational damage in man from consanguineous marriages. Proc. Natl. Acad. Sci. USA 42:855-863.

Myra, M., K. MacKenzie, and S.P. Vander Kloet. 2004. Investigation of a possible sexual function specialization in the lowbush blueberry (Vaccinium angustifolium Aiton. Ericaceae). Small Fruits Rev. 3: 313-324.

Nei, M. and W.H. Li. 1979. Mathematical model for studying genetic variation in terms of restriction endonucleases. Proc. Natl. Acad. Sci. USA 76:5269-5273.

Nuortila, C., J. Tuomi, J. Aspi, and K. Laine. 2006. Early-acting inbreeding depression in a clonal dwarf shrub, Vaccinium myrtillus, in a northern boreal forest. Ann. Bot. Fenn. 43:36-48.

Nuortila, C., J. Tuomi, and K. Laine. 2002. Inter-parent distance affects reproductive success in two clonal dwarf shrubs, Vaccinium myrtillus and Vaccinium vitis-idaea (Ericaceae). Can. J. Plant Sci. 80:875-884

Ortiz, R. and A. Golmirzaie. 2002. Hierarchical and factorial mating designs for quantitative genetic analysis in tetrasomic potato. Theor. Appl. Genet. 104:675-679.

Park, Y.S. and D.P. Fowler. 1982. Effects of inbreeding and genetic variances in a natural population of tamarack [Larix laricina $(\mathrm{Du}$ Roi) K.Koch] in eastern Canada. Silvae Genet. 31:21-26.

Quimio, C.A. and F.J. Zapata. 1990. Diallel analysis for combining ability over several environments. Indian J. Genet. Plant Breed. 33: 469-481.

Rimando, A.M., W. Kalt, J.B. Magee, J. Dewey, and J. Ballington. 2004. Resveratrol, pterostilbene, and piceatannol in Vaccinium berries. J. Agr. Food Chem. 52:4713-4719. 
Rowland, L.J., A.L. Dhanaraj, J.J. Polashock, and R. Arora. 2003a. Utility of blueberry-derived EST-PCR primers in related Ericaceae species. HortScience 38:1428-1432.

Rowland, L.J., S. Mehra, A. Dhanaraj, E.L. Ogden, and R. Arora. 2003b. Identification of molecular markers associated with cold tolerance in blueberry. Acta Hort. 625:59-69.

Rowland, L.J., S. Mehra, A. Dhanaraj, E.L. Ogden, J.P. Slovin, and M.K. Ehlenfeldt. 2003c. Development of EST-PCR markers for DNA fingerprinting and genetic relationship studies in blueberry (Vaccinium, section Cyanococcus). J. Amer. Soc. Hort. Sci. 128: 682-690.

Seavy, S.R. and K.S. Bawa. 1986. Late-acting self-incompatibility in angiosperms. Bot. Rev. 52:195-219.

Shattuck, V.I., B. Christie, and C. Corso. 1993. Principles for Griffing's combining ability analysis. Genetica 90:73-77.

Sneath, P.H.A. and R.R. Sokal. 1973. Numerical taxonomy. Freeman, San Francisco, CA.

Sorensen, F. 1969. Embryonic genetic load in coastal douglas fir, Pseuodotsuga menziesii var. menziesii. Amer. Nat. 103:389-398.

Strik, B. 2006. Blueberry production and research trends in North America. Acta Hort. 715:173-183.

Turner, M.E., J.C. Stephens, and W.W. Anderson. 1982. Homozygosity and patch structure in plant populations as a result of nearestneighbor pollination. Proc. Natl. Acad. Sci. USA 79:203-207.

Vander Kloet, S.P. 1976. A comparison of the dispersal and seedling establishment of Vaccinium angustifolium (the lowbush blueberry) in Leeds County, Ontario and Pictou County, Nova Scotia. Can. FieldNaturalist 90:176-180.

Vander Kloet, S.P. 1978. Systematics, distribution, and nomenclature of the polymorphic Vaccinium angustifolium. Rhodora 80:358-376.
Vander Kloet, S.P. and P. Cabilio. 1996. Ten year study of the annual variation in berry and seed production in a population of Vaccinium corymbosum L. Amer. Midl. Nat. 135:349-356.

Widstrom, N.W., K. Bondari, and W.W. McMillian. 1992. Hybrid performance among maize populations selected for resistance to insects. Crop Sci. 32:85-89.

Willi, Y. and J. Van Buskirk. 2005. Genomic compatibility occurs over a wide range of parental genetic similarity in an outcrossing plant. Proc. R. Soc. Lond. 272:1333-1338.

Wolfe, K.L. and R.H. Liu. 2007. Cellular antioxidant activity (CAA) assay for assessing antixidants, foods, and dietary supplements. J. Agr. Food Chem. 55:896-907.

Wood, G.W. 1968. Self-fertility in the lowbush blueberry. Can. J. Plant Sci. 48:431-433.

Wright, A.J. 1985. Diallel designs, analyses, and reference populations. Heredity 54:307-311.

Yarborough, D. 2004. Factors contributing to the increase in productivity in the wild blueberry industry. Small Fruits Rev. 3:33-43.

Yarborough, D. 2009a. Wild blueberry fact sheet: Wild blueberry culture in Maine. Univ. Maine Coop. Ext. Fact Sheet No. 220.

Yarborough, D. 2009b. Wild blueberry crop statistics from 1924 to 2008. 1 Feb. 2010. <http://wildblueberries.maine.edu/factsheets.htlm\# crop>.

Zar, J.H. 1999. Biostatistical analysis. 4th Ed. Prentice Hall, Upper Saddle River, NJ.

Zhang, Y. and M.S. Kang. 1997. DIALLEL-SAS: A SAS program for Griffing's diallel analyses. Agron. J. 89:176-182.

Zhang, Y., M.S. Kang, and K.R. Lamkey. 2005. DIALLEL-SAS05: A comprehensive program for Griffings and Gardner-Eberhart analyses. Agron. J. 97:1097-1106. 